\title{
Analysis of China's Emergency Management System Reform from the Perspective of Big Data
}

\author{
Tingyang $\mathrm{Li}^{1,2,3 *}$ \\ ${ }^{1}$ China Research Center for Emergency Management, Wuhan University of Technology, Wuhan, China \\ ${ }^{2}$ School of Safety Science and Emergency Management, Wuhan University of Technology, Wuhan, China \\ ${ }^{3}$ Hubei Collaborative Innovation Center for Early Warning and Emergency Response Technology, Wuhan, China \\ Corresponding Author’s Email: lisir715@whut.edu.cn
}

\begin{abstract}
In order to figure out the current problems of emergency management and pre-plans in most cities, this paper analyzes and discusses the significance of the big data era, the traditional emergency management thinking mode and the emergency management thinking mode under the big data horizon. The purpose of the work is to propose effective methods of constructing the emergency system in the era of big data.
\end{abstract}

Keywords-big data; emergency management; thinking; transformation

\section{INTRODUCTION}

In recent years, China's social economy has developed rapidly, and the process of urbanization has also accelerated. Various systems are included in the city, such as finance, education, health care, government, etc. These systems are independent but interconnected. In the process of accelerating urbanization, perfect emergency management and plans are needed [1]. However, the current emergency management and pre-plans in most cities are not perfect, and there are still some problems. Therefore, it is necessary to adopt sound emergency management and plan to transform the thinking of emergency management under big data.

\section{The SignificAnce Of Big Data}

The development of today's society requires a comprehensive grasp of the information. The characteristics of the big data era are that the amount of data is very large, and at the same time, the interoperability of global information is more convenient [2].

\section{A. Promoting the integration of multiple disciplines and majors}

The era of big data has spurred the disciplines of nature and society to be independent and to blend [3]. The division of labor in various professions has indeed played a certain role in the traditional era, but with the development of society, management is more complicated. If the profession is still divided and the division of labor is too fine, many problems will arise, such as the emergence of professional barriers [4]. Under big data, people can rationalize complex networks through huge data, quickly find target data and confirm and analyze it, so that complex social management problems can be solved.

\section{B. Transforming the extensive social governance to the refined one}

In the era of big data, the database is very comprehensive, and the relevant departments of social management can find the information they need in the huge data so that the efficiency of the work can be improved, and in the process of social governance, it can be formulated according to the local reality and the characteristics of the residents. Corresponding urban services, achieving refined social governance and changing the traditional way of extensive.

\section{Improving the scientific nature of government decision- making}

In the era of big data, the spread of network information is very rapid, and some information spread on the Internet before it proves authenticity, which is easy to cause a public crisis. Government departments can use big data technology, find social hotspots in huge data, find out the causes of the crisis, and why the spread is carried out so that the truth of the crisis can be restored. Besides, the government can also grasp and analyze the hot spots of public concern according to the information records that people browse on the Internet, to ensure that the decisions are in line with public opinion and are scientific.

\section{THE TRADITIONAL WAY OF THINKING EMERGENCY MANAGEMENT}

To comply with the trend of international emergency management development, the primary task of each country is to build a special emergency management organization [5]. However, there are corresponding problems in China: in the establishment of institutions, the departments that manage individual disasters are mainly established; in power control, China does not establish a state of emergency law. In an emergency, it is easy to generate government and the public, the central government. The responsibilities of the government and local governments are unclear, the procedures for exercising powers and performing duties are unclear, and emergency measures are not in place. In the main body of participation, it is mainly based on government-led participation [6]. In the organizational command mode, China is "top-down". However, there are no effective "bottom-up" means of information transmission and technology; in the 
contingency plan, because of the fragmentation, there is no organic integration between the existing emergency plans; in terms of technical support systems, China At present, there is a lack of a complete and well-coordinated technical support system, and there is no effective technical support in making emergency decisions.

\section{A. Problems in the design of China's emergency management system}

Modern society is a risk society, and all kinds of emergencies are more complex and related than the original. Therefore, it is necessary to design a comprehensive and comprehensive emergency response system. The design of the emergency system requires corresponding management thinking, methods and means, while also relying on professional and strong science and technology and talents. In the design process of China's emergency management system: First, "heavy response, light management", because our emergency system is designed based on the "Emergency Response Law", the core concept is to build a skilled and efficient response. The system of sudden incidents ignores the prevention and monitoring of the whole process in addition to the response, which also results in the serious lack of construction of other links besides the response. Second, "heavy power, light science", the current emergency system mainly focuses on the division of power between government departments and between different powers, and the identification of responsibilities. It rarely involves the participation of emergency management based on modern advanced scientific concepts and information technology. This has caused the level of specialization in emergency management in China to be far from enough.

\section{B. Poor continuity in the existing system operation mode}

Since the "Emergency Office" only undertakes a single "coordination" function, after the emergencies, there is an urgent need for a strong, unified command system to respond to the work, so in the event of a public crisis, in accordance with the existing emergency in China The system, the "command department", a temporary organization, was born, and its responsibility is to coordinate the overall situation of emergency management and emergency rescue. Therefore, China's emergency management system has formed a mode of operation in the reality of the gap, namely, "Emergency Office + Command" Department mode. This model has played a certain role in the process of dealing with major emergencies in China, but it has the following problems: First, in the process of handling emergency management, "re-handling, light management", In the event of an emergency, departments at all levels are always busy, and often delay the timing of crisis management, resulting in a major disaster. Second, in the process of "Emergency Office + Command", regardless of cost, it is extremely unreasonable. Third, it relies too much on political mobilization and armed forces, military theory, and lack of mobilization ability for citizens. The power of the "Emergency Office" is lacking, and the "Command" is lacking and disposing of after successful handling of emergencies. The "political mobilization" ability that should be combined has caused the inefficiency of the emergency management system in China, attaches importance to "response" and despise "comprehensive management", which means that the sustainability of the emergency system is poor.

\section{Professional division of labor leads to information asymmetry}

The traditional "bureaucratic system" has profoundly affected the operation of our national emergency system.

This kind of emergency management model based on the professional division of labor helps to improve the degree of specialization in emergency management. However, the longterm professional division of labor has led to the formation of a separate emergency response system. At the same time, information barriers have been formed between various government departments, information communication is not smooth, and departmental interests restrict the construction and improvement of the emergency management system. In the case of increasingly complex incident handling, such sectorial barriers are not conducive to the overall coordination and coordination of emergency management. At the same time, the impact of sudden disasters is social, and the division of sectors alone cannot be effectively disposed of.

\section{Excessive interference of local interests leads to information asymmetry and distortion}

China's handling of emergency management is based on the local government's discovery of emergencies. The source will report to the provincial "Emergency Office" through the local government and then report to the relevant functional departments of the State Council by the provincial "Emergency Office”. After approval and approval, the task will be assessed downwards. However, there are problems of interest between local governments in China, so that a considerable number of emergencies, and the subsequent large-scale crisis disasters that have occurred nationwide, initially caused problems at the local level. However, under the current emergency management system, when governments at all levels deal with emergency management matters, they first consider the impact of their economic interests and political interests and rarely look at emergency management information from a comprehensive and scientific perspective. Delivery and information management, local governments are often in the protection of local interests to interfere with and distorted information. Based on information distortion and asymmetry, the local government's action logic is that because of the guidance of local interests, the information of the emergencies is disorderly reported, which causes the early emergency response to be unsatisfactory so that a larger scope is generated later. The crisis, so that the higher-level government has come forward to clean up the situation, so delaying the emergency management and disposal period will result in a large amount of waste of resources, loss of life and property, and the government's credibility will decline, and there will be no harm.

\section{THE REFORM MEASUREMENT OF CHINA'S EMERGENCY MANAGEMENT SYSTEM}

Since the tradition "bureaucratic system" cannot continue to serve the new era, at the same time, the data collection, organization, storage, analysis and other functions of big data 
technology increasingly affects management [7]. This article will focus on big data technology and thinking. The emergency management and disposal departments should start reforms from the following aspects:

\section{A. Emergency management agencies need data scientists to improve decision-making ability}

Because the emergency management of modern society is a specialized and highly technical country. At the household level, traditional public departments and public officials are difficult to effectively dispose of and participate in the entire process of management. Therefore, in the process of institutional setting, it is not only possible to set the emergency management department as a general public function department, but also to position the emergency management department as a professional comprehensive department with R\&D and scientific research. At the same time, the data encountered by government departments in China is increasing day by day, and the demand for data management and use is also very large. Therefore, the state needs to integrate the information work department into the emergency management department to play its professional data collection, organization, storage and integration, mining, analysis, and utilization capabilities. The step of "integrating functional organizations" is not enough. It is also necessary to recruit and train many data analysis scientists and designate chief data scientists. Accenture has predicted that "data analysts" are the most profitable professions of the 21st century. Only in this way can big data technology and thinking be applied to the entire process of emergency management to help the government's emergency management "flattening".

\section{B. Optimizing information collection capabilities as the beginning of big data emergency management}

Optimize information collection capabilities for emergency management systems centered on big data construction is especially needed. First, the essence of big data is based on massive information collection, mining, and processing. Second, optimizing information collection capabilities can help emergency management decision-making organizations to make better emergency decisions. Third, optimizing information collection capabilities can help build a big data emergency management information system. Information collection, as the beginning of big data emergency management, is especially important for the construction of the emergency system and emergency decision-making. Therefore, we must do a good job. First, take citizens as the center and establish a system of information reporting and collection based on citizens and other organizations. The source of many crises is discovered by the bottom layer; second, the Internet of Things, mobile Internet, etc., such as probes, sensors and other technologies to collect information, such as the installation of a large number of seismic sensors in the Pacific Rim seismic zone in California, Monitor earthquakes and collect emergency information. Third, massive information can help us predict the disasters.

\section{Enhancing the ability of information integration, building a big data emergency management information system}

To improve the integration of emergency management information, the government must build a big data emergency management system in both horizontal and horizontal directions. In the vertical direction, the central government urgently needs to help local governments to build emergency management information systems under big data, and replace the identity of power coordinators at all levels and departments with the role of information service providers. Local governments in China lack certain emergency information response mechanisms and cannot collect and integrate data, so that they cannot rely on information and collected data for emergency decision-making. However, based on the fact that the grassroots government cannot handle emergency management incidents in a timely and effective manner, small emergencies will be transformed into large emergencies, which will make it more difficult to make emergency management and emergency rescue, and at the same time consume manpower, material resources, and power. The coordination will be more. Therefore, to increase the local government's emergency information, data collection, organization, integration and use capabilities, the higher-level central government should help local governments to build an emergency management information system centered on big data technology, thereby increasing their emergency management capabilities. In the horizontal direction, the traditional "bureaucratic system"-based functional department management method has been difficult to apply to the construction of modern emergency management systems. Information asymmetry and information barriers between horizontal departments have increased the number of major events. The difficulty of handling emergency management. Therefore, it is necessary to increase the integration and coordination capabilities of the horizontal departments. According to Linden's "seamless government theory", it is necessary to help the government departments to build a seamless big data-based emergency management information management system. It is also necessary to come forward with a national-level emergency management agency to break the interests of the department and reshape the pattern. Only the emergency management information system based on horizontal and vertical levels can be integrated to help improve China's response emergency management system.

\section{Deepening the awareness of information disclosure and} opening the emergency management database to the public

Information disclosure refers to the public asking for information from the government, and the government agrees and provides information to the public. This is a different kind of information release, the way the public gets information. The emergency management of modern society is not just a matter for the government; it is about the safety of citizens' lives and property. The monopoly on emergency management information is not conducive to the operation of the emergency management system. Second, the political level has reduced the credibility of the government. Therefore, in the context of the construction of an emergency management system with big data as the core, an emergency management information database is established to disclose information to the public 
national big data development strategies, increase investment

First, because the government and the public organizations obtain emergency information and respect their right to know, their credibility must be improved. Second, the disclosure of emergency management information will inevitably lead to the study of emergency management by the relevant entities, and it is the emergency management system of China. Construction of "planning and planning. Third, the disclosure of emergency management information will lead to further supervision of the society, supervise the government's ability to handle public affairs, and make emergency management more standardized. Therefore, it is very beneficial to open the emergency management database to the public.

\section{CONCLUSION}

In summary, emergency management belongs to the scope of government public management. In today's big data era, the government's emergency management should be consistent with the requirements of the times, change the emergency management thinking, correctly understand and use big data, and promote the emergency management system. Improve the level of emergency management.

Based on the background of the research, this paper analyzes the related problems in the construction of China's emergency management system and based on big data technology and thinking has made corresponding countermeasures for the construction of China's emergency management system. At the same time, the application to emergency management has the following prospects: First, China should follow the development of the United Kingdom, the United States, and other developed countries, formulate in big data; second, develop open policies for big data. To enhance data sharing capabilities; third, based on big data thinking and technology, to better explore its role in the emergency management process; finally, the balance between public safety and citizen privacy is also worth pondering by the government and citizens.

\section{REFERENCES}

[1] Hu Shugen, Shan Lidong, Xu Jingwei, Research on the characteristics of wisdom public decision-making based on big data [J], Journal of Zhejiang University, 2015(3).

[2] Li Danyang, A preliminary study on the reform of China's emergency management system under the background of big data [J], Jianghai Journal, 2014(2).

[3] Ma Ben, Mao Qingyu, Application of Big Data in Emergency Management [J]. China Administration, 2015 (3).

[4] Zhang Xinmei, Chen Guohua, Zhang Hui, Chen Qingguang, Yan Weiwen, Research on the problems of China's emergency management system and its development countermeasures [J], Chinese Journal of Safety Science, 2006(2).

[5] Lu Yuchi, Analysis of China's emergency management system reform from the perspective of big data [J], Modern Business, 2016, (23): 117118.

[6] Ning Xin, Research on government emergency management in the era of big data [J], Journal of Xiamen Radio and Television University, 2017, (02): 23-26.

[7] Li Danyang, Reform of China's Emergency Management System in the Age of Big Data [J], Journal of South China Normal University (Social Science Edition), 2013, (06): 106-111. 